\title{
Determinants of Sustainability of Rural Agricultural Projects in Rwanda: Case of Maize Projects in Budubi Irrigation Scheme in Nyanza District
}

\author{
MUHONGERWA Alice
}

Master of Business Administration in Project Management of the University of Kigali.

\begin{abstract}
This study aimed at assessing the influence of financial input on the sustainability of maize projects in Budubi Irrigation Scheme; to investigate influence of Irrigation Scheme management on the sustainability of maize projects in Budubi Irrigation Scheme; to examine influence of benefits from maize on the sustainability of maize projects in Budubi Irrigation Scheme and to assess influence of care for environment on the sustainability of maize projects in Budubi Irrigation Scheme. The study was guided by the sustainability theory and applied a descriptive cross-sectional design, and population of 392 persons out of which a sample of 198 was applied. Document review, questionnaire, interview, and observation methods were used to collect data, while descriptive statistics and content analysis was applied for data analysis.
\end{abstract}

Key words: Irrigation scheme, sustainability, agricultural projects, Maize projects.

\section{Introduction}

Research has shown that in many African, Caribbean and Pacific Countries, agriculture is the main source of rural livelihood. The Food and Agriculture Organization of the United Nations (FAO, 2015) reports that close to $80 \%$ of those living in rural areas rely on farming for their livelihood. Majority of them are smallscale farmers, who farm on less than 5 ha of land on average. In recent years, there has been a global focus on smallholder farmers that has seen experts devise innovative methods to improve their productivity, and companies strive to better integrate smallholders in global agricultural projects (Polnac\&Pomerey, 2015). Nonetheless, there is evidence that project implementation in sub-Saharan Africa has often shown low levels of sustainability (Gebrehiwot, 2006). According to Meinzen-Dick (2007), it is estimated that results of many sustainability projects are not evident for 15-20 years. This is partly due to inappropriate policy or legislation, insufficient institutional support, unsustainable financing mechanisms, ineffective management systems, and lack of technical control measures (Niyi et al., 2007). This is why it has been underscored that stakeholders like local communities, public sector, private sector, nongovernmental and civil society organizations, development practitioners and researchers need to work together to address these challenges (Pell, et al., 2010).

The value of agricultural projects in relation to the fight against poverty among the rural families has been underscored in the Strategy to Revitalize Agriculture (SRA). The declining effectiveness of the agricultural projects practices has been identified as one among the factors impeding agricultural farm productivity projects in different countries. Successful project implementation would entail timely implementation, within budget, with accountability and delivery of the desired results (Karanja, 2013).

According to Thilmany (2014), success of projects depends on the ability to develop fully integrated information and control systems to plan, availability of resources, stakeholder participation, monitoring and control that can facilitate problem solving and decision making processes. Determination of a successful project outcome is measured by the extent to which the project accomplished complex endeavours that meet a specific set of objectives within the constraints of resources, time, and performance objectives. Project management aims to ensure the effective use of resources and delivery of the project objectives on time and 
within cost constraints. It entails the planning and controlling the various events that together comprise the project (Thilmany, 2014).

In developed countries, agricultural projects management has been shown to result in more satisfied consumers, stronger business relationships, reduced costs and more profitability. With a significant portion of the world's poor dependent on rural and agricultural livelihoods, the development of dynamic agricultural projects can play a vital role in reducing poverty by creating jobs and income. Agriculture has long been a key sector in the Peruvian economy, representing 9\%-10\% of Gross Domestic Product (GDP) over the past 12 years (USAID, 2009).

In Eastern African countries like Kenya, the performance of the agricultural projects in Kenya has been a controversial subject (Irungu\&Makori, 2016). The project systems have been perceived as top-down, inflexible and considered a major contributor of the poor performing agricultural sector. Thus, there has been a desire to reform agricultural projects financing practices into a system that is cost effective. The agricultural projects financing practices that do not significantly contribute to improving the lives of its clientele is inappropriate (Irungu\&Makori, 2016).

In Rwanda, small scale farmers have traditionally benefited from agricultural projects implemented by the government of Rwanda whereby the ministry in charge of agriculture has played a leading role. These projects focus mainly on food crops and livestock. The government has tried a number of extension models and styles, including the progressive (or model) farmer approach, integrated agricultural rural development approach, farm management, training and visit, attachment of officers to organizations, farming systems approaches and farmer field schools. All these approaches have emerged with varying levels of challenges on performance (MINAGRI, 2015); and irrigation projects have not been an exception.

The success rate of the agricultural related projects to their original plans, is somewhere between 30 and 50 percent. Recent data show that despite the high economic growth, poverty rates have not fallen proportionately, declining only by $3.5 \%$, from $60.4 \%$ to $56.9 \%$ between 2008 and 2012 (MINAGRI, 2015).. The continuing high levels of poverty can be attributed to low levels of growth in agricultural productivity due to poor implementation of agricultural project and fail of some agriculture project in Rwanda. Out of the 110 projects initiated in the year 2012 and 2015, among them livestock farming, horticultural farming, bee keeping and home economics, 32 of the projects were terminated due to issues related to project management such as project team, stakeholder's participation, financing, monitoring and evaluation and top management support (MINAGRI, 2015).

\section{Literature}

According to Brundtland (2014) sustainable development is the development that meets the needs and aspirations of the present without compromising the ability of future generations to meet their own needs. Thus, sustainable aspect is the organizing principle for sustaining finite resources necessary to provide for the needs of future generations of life on the planet. It is a process that envisions a desirable future state for human societies in which living conditions and resource-use continue to meet human needs without undermining the integrity, stability and beauty of natural biotic systems.

Sustainability is a key aspect of any development initiative or discourse. Sustainability can be defined as the practice of reserving resources for future generations without any harm to nature and other components of it. Sustainability ties together concern for the carrying capacity of natural systems with the social, political, and economic challenges faced by humanity (Brundtland 2014). Focus is also placed on the present generations' responsibility to regenerate, maintain and improve planetary resources for use by future generations. It can also be defined as any construction that can be maintained over a long period of time without damaging the environment and the development balancing near-term interests with the protection of the interests of future generations (Brundtland 2014).

Project sustainability is the capacity of a project to maintain services and benefits to the community without detrimental effects even after special assistance such as financial, technical and managerial has been phased out. It is the probability that a project shall continue long after the outside support is withdrawn (Narayan, 1993).A project is sustainable if the community/beneficiaries are capable on their own without the assistance 
of outside development partners, to continue producing results for their benefit for as long as their problem still exists (Luvengaet al., 2015). On the other hand, IFAD (2007) defines project sustainability as the ability to ensure that the institutions supported through projects and the benefits realized are maintained and continue after the end of the project's external funding.

While the trend with implementation is showing significant improvement, the trend with post implementation sustainability is rather disappointing increasingly, fewer projects are being sustained. This means that while huge expenditures are being incurred by these countries in implementing projects, poor sustainability is depriving them from the returns expected of these investments. This further means that while the debts from development expenditure are increasing, gains from these expenditure have either not been forthcoming fully or been accrued at a lower rate (World Bank, 2017).

Toward sustainability of project management process; every organization both profit or non-profit organization, has its objectives and goals in mind to achieve their goal in order to satisfy the social need of the beneficiaries and in the effort to achieve these purposes supervision more often than not play a vital role (Carrol Richardson, 2013). Therefore, project sustainability is an integral part of our day-to-day operational management, it is used to continuously working ability, access and progress made with the project when viewed against its goals and objectives; involves the logical framework through which projects track inputs, processes, activities, outputs and outcomes.

A project is considered sustainable when it continues to deliver benefits to the project beneficiaries for an extended period after the financial assistance will be terminated. It is therefore a continuation of a project's goals, principles, and efforts to achieve desired outcome ensuring that the goals of the project continue to be met through activities that are consistent with the current conditions and workforce development needs of the region, including the needs of both workers and industry (Gallagher A.; Johnson D.; Glegg G. and Trier C., 2014). Project sustainability comprises three core pillars social, economic and environmental and is the capacity for all three to endure simultaneously (Redclift, 2010).

The three pillars of sustainability as stated above, imply that to enhance project sustainability a rigorous sustainability analysis is needed at the time of formulation of a project or a programme. It is expected that such an analysis which is to be followed up by development of a sustainability strategy will assist in incorporating the elements of sustainability, right at the design stage of a project (Erytin, 2015). Sustainability analysis is the identification and analysis of degree of presence or absence of the factors that are likely to impact, either positively or negatively on the prospects of sustained delivery of project benefits (Erytin, 2015).

Planning for sustainability presents a tool for checking the aspects of sustainability, at the time of designing of a project. The 'Check List' which include a member of analysis, such as economic and financial analysis; social analysis etc, are important and should be undertaken to ensure incorporation of sustainability enhancement inputs during the preparation and the design stage of a project, where these analysis include the following (Erytin, 2015).:
i. Relevance
ii. Acceptability
iii. Economic viability
iv. Financial viability
v. Environmental sustainability
vi. Implementation and sustainability strategy
vii. Post-implementation operation and maintenance.

The aspect of relevance refers to review of consistency (or lack of it) between the objectives of the proposed project with national, sectoral, provincial and district priorities. Quite often, it is seen that when a project is taken up without due regard to various priorities set by the government, its ability to attract required support from various parties and its capacity to operate in a conducive environment, gets severely restricted. 
Therefore, 'Relevancy' test is expected to help analyzing these issues and assess the relationships between the proposed actions and their consistency with different priorities that have been set by the government (Erytin, 2015).

Acceptability issues relate to the level and degree of acceptability of a project to the community, the local representatives, the executing agency etc. Weak acceptability by anyone or more of these parties has the risk of compromising long term sustainability of a project. Economic/Financial viability refers to economic and financial profitability of project induced products and services. For these products to be of benefits, both to the producers as well as the economy the product cost must reflect real market costs and the product prices, the real market prices and that the latter should be consistently higher than the former. In some cases, the project induced products and services may not reflect the market cost and nor the price which may mean that which the project will benefit the direct participants or the target population; then it will incur economic losses at the national level (Erytin, 2015).

It is now widely recognized that under the current situation of globalization and liberalization, any project induced products which cannot be produced and sold under market determined cost and prices and cannot earn profit under these conditions, are neither likely to be sustained nor would these be beneficial to the economy. Environmental sustainability relates to project induced environmental impacts both positive and negative. If negative impacts are foreseen and no mitigation measures are planned, then ultimately the project may yield benefits at a reduced rate or worse still and depending on the extent of environmental costs, such negative impacts may in fact contribute to the net losses to the economy (Erytin, 2015).

According to Erytin (2015), implementation and Sustainability strategy refers to consideration of project management arrangements including a clear implementation period, a well-defined implementation plan with clearly defined functions and responsibilities and necessary provisions having been made. Weak project management and inadequate sustainability provisions contribute to implementation problems which than weakens the project sustainability.

Post implementation operation and maintenance (O\&M) refers to management support (either by the executing agency or the community or both) required after implementation of a project. Quite often projects tend to encounter sustainability problems due to weak or inadequate O\&M support. The sustainability analysis is to be followed by development of a sustainability strategy, so as to ensure that all sustainability enhancing elements are incorporated right at the design stage of a project (Erytin, 2015).

\section{Empirical Reviews}

In 2013, Chizimba focused on the sustainability of donor funded projects in Malawi. The findings from the study suggested that a project is said to be sustainable if only it has an in build exit strategies and also if sustainability is to be achieved, the intervention should engage the community and build capacities of local government for effective delivery of project benefits. He demonstrated that to achieve this, working in partnership and or collaboration was not an option is must in any intervention. The study also recommended that, the community needed to be fully informed about the project exit strategies. The study put more emphasis on the community involvement but mainly focused on information giving while for the project to be sustainable the community was supposed to be involved in all phases of project cycle including in designing the exit strategy so as to maintain and strengthen the intervention impact.

Another study on sustainability was done by Deogratias (2013) who studied community participation in and sustainability of national water projects in Chalinze, Tanzania. The study was conducted in Chalinze whereby 130 respondents were selected to obtain both quantitative and qualitative data. Structured questionnaires, focus group discussions, observation, interview of key informants and documentary reviews were used to obtain relevant information. Checklists and observation kits were used for interviews and focus group discussion and observation. The findings show that, the community participation in planning and implementation of Chalinze Water Supply project was poor; as well as monitoring mechanism of operation and management and community participation on decision-making was not satisfactory. This study by Deogratias (2013) does not explain how the poor participation of the community affected the project. This way, it may be difficult to reach conclusive decisions. 
Diana (2009) did a study on sustainability of development projects. Diana (2009) studied management and regulation for sustainable water supply schemes in rural communities in Tanzania and revealed that community participation and ownership have a valuable role to play in achieving sustainability but can also create other challenges. How realistic then is participatory decision making where community members have little understanding on various management and technological options and their implications on the long run. However Diana (2009) did not explore exactly what role community participation and ownership played in the sustainability of these projects.

\section{Methodology}

According to Trochim and William (2006), are search design refers to the overall strategy that you choose to integrate the different components of the study in a coherent and logical way, thereby, ensuring you will effectively address the research problem. It is actually a blueprint for the collection, measurement, and analysis of data.

This study adopted a descriptive cross-sectional study design. The study involved collection of data at a single point in time in the target population. Descriptive means that the study was able to describe a phenomenon as it is without doing any form of manipulation.

According to Kothari (2011), a study population is a well-defined or specified set of people, group of things, households, firms, services, elements or events which are being investigated. Thus, the population should fit a certain specification, which the researcher is studying and the population should be homogenous.

\section{Population size}

\begin{tabular}{|l|l|l|}
\hline S/N & Category & Population size \\
\hline & Farmers & 380 \\
\hline & Budubi Irrigation Scheme Management & 3 \\
\hline & Horticulture in Reality Corporation Staff & 2 \\
\hline & Local Leaders & 5 \\
\hline & MINAGRI Officers & 2 \\
\hline & Total & $\mathbf{3 9 2}$ \\
\hline
\end{tabular}

Mugenda \& Mugenda (2010) defined a sample as a smaller group or sub-group obtained from the accessible population. Yamane (1967) provided a simplified formula to calculate sample size. This formula is used to calculate the sample size from a population of 390.

$$
\frac{N}{1+N(e)^{2}}
$$

A 95\% confident level and $\mathrm{p}=0.5$ were assumed for the equation where $\mathrm{n}$ is the sample size, $\mathrm{N}$ is the population size, and e is the level of precision. The sample size is calculated at $95 \%$ confidence level, an alpha level of 0.05 which is margin of error of $\pm 5 \%$ and 0.5 as the standard deviation which shows how much variance expected in as responses.

When applied, the formula gives us: $390 \div 1+(390 \times 0.05 \times 0.05)=198$

The study collected data on 198 respondents who are associated with the maize projects in Budubi Irrigation Scheme in Nyanza District. 
The researcher collected data through questionnaire, interviews, observation and document reviews.

A researcher used semi-structured interviews to explore and reconstruct events explained through the lived experience and perspectives of the participants. Shared characteristics of interviewing techniques are the rich details and information was provided in the interviews, the flexibility to elaborate, adjust, and deviate from the order while answering open-ended questions.

Document review was used to obtain data that the respondents were not able to provide through other methods for various reasons such as forgetting or sensitivity reasons. These included project reports, budgets, and work plans, baseline surveys, and evaluations, books of accounts, registers and minutes of meetings of committees. Documentary review was used to collect secondary data.

This study utilized a questionnaire with open and close ended items some of which were on the Likert scale. Likert scale is an interval scale that specifically uses five anchors of strongly disagree, disagree, neutral, agree and strongly agree. The Likert scale measures the level of agreement or disagreement and is good in measuring perception, attitude, values and behaviour. The Likert scale has scales that assist in converting the qualitative responses into quantitative values (Mugenda \& Mugenda, 2003).

\section{Findings, Discussion and Interpretation}

The first objective was to assess the influence of financial input on the sustainability of maize projects in Budubi Irrigation Scheme.

After the analysis and interpretation of the data; the research revealed that Irrigation remains a critical input into farming and, therefore, it remains a proxy for food security and poverty alleviation in developing countries. Despite their role in economic growth and the received investment, irrigation schemes are still underperforming. Among many irrigation schemes, transferring more management responsibilities to farmers proved to be a viable path toward improving performance. However, the large diversity of implementation strategies makes evaluation difficult, while its well-demonstrated benefits have paramount importance to convince reluctant smallholders to take additional roles.

Financial input on sustainability of maize projects in Budubi Irrigation Scheme.

\begin{tabular}{|c|c|c|}
\hline Social contribution & Frequency & Percentage \\
\hline Creation of cooperative & 81 & 92.1 \\
\hline Injection of Cash inflows & 75 & 85.2 \\
\hline Repairing and construction of infrastructures & 71 & 80.7 \\
\hline Participation in activities of all Budubi project & 67 & 76.1 \\
\hline
\end{tabular}

The findings shows that the financial inputs resulting from creation of cooperatives, where $92.1 \%$ of respondents agree with that Creation of cooperative,85.2\% of respondents agree with that Repairing and construction of infrastructures, $80.7 \%$ of respondents agree with that Participation in activities of all Budubi project ,76.1\% of respondents agree with that Participation in activities of all Budubi project leads to sustainability of maize projects in Budubi Irrigation Scheme.

The second objective was to investigate the influence of Irrigation Scheme management on the sustainability of maize projects in Budubi Irrigation Scheme. In Budubi, irrigation helps to grow maize crops, maintain landscapes, and revegetate disturbed soils in dry areas and during periods of less than average rainfall. Irrigation also has other uses in crop production, including frost protection, suppressing weed growth in grain fields and preventing soil consolidation. Agriculture is often greatly hampered due to irregular, insufficient or uncertain rain. Proper irrigation systems can secure uninterrupted agriculture.

\section{Availability of an Irrigation Project BUDUBI}




\begin{tabular}{|c|c|c|}
\hline Availability & Frequency (F) & Percentage (\%) \\
\hline & & \\
\hline Yes & 98 & 94.9 \\
\hline No & 5 & 5.1 \\
\hline & & $\mathbf{1 0 0 . 0}$ \\
\hline
\end{tabular}

It is evident from the data that majority of the farmers $98(94.9 \%)$ who participated in the study agreed that there is irrigation project in Budubi while $5(5.1 \%)$ disagreed. This shows that irrigation is a major economic activity. This is supported by the fact that the area receives insufficient rainfall to support rain fed crop production. The findings show that majority of the farmers 58(56.4\%) who participated in the study agreed that the irrigation project is operational while $45(43.6 \%)$ disagreed. The findings point out most of the irrigation projects are operational. It also shows that a big number of projects have stalled. This is an indication that there are challenges that force many of these projects to stall and if the challenges can be discovered and solved then this can influence positively to the sustainability of the projects.

The third objective was to examine influence of benefits from maize on the sustainability of maize projects in Budubi Irrigation Scheme. From the research findings, access to indispensable inputs such as improved seed Varieties and fertilizer has a significantly positive influence on Sustainability of Agricultural Projects in BUDUBI with a mean score of 3.9628. This signifies that they are the most important factors that determine Sustainability of maize projects in the area which are not accessible to farmers due to high cost and also scarcity of these inputs. Other significant factors are lack of sustained contact and cooperation with other public organizations such as trade (labour) unions and farmer's groups $(\mathrm{m}=3.0)$ and access to extension services and supportive policies to help these households become more productive and enter commercial markets to generate income. (3.3465). Less significant factor was access to equipment, to which the farmers agreed that nobody has ever provided to them $(\mathrm{m}=2.9302)$.

\section{Conclusion And Recommendation \\ Conclusion}

Based on the objectives and findings of the study the following conclusions were made. Based on the first objective financial input on the sustainability of maize projects in Budubi Irrigation Scheme. This can be achieved through looking for more sources of financial inputs to be able facilitate the irrigation programme in Budubi. Based on objective number two, the influence of Irrigation Scheme management on the sustainability of maize projects in Budubi Irrigation Scheme, this can be achieved through construction of dams to collect the commodity during rain period to be used in dry spell. There should also be qualified technical staff to repair and maintain the water systems. Spare parts should also be availed to facilitate a quick fix in case of any breakage. This will greatly influence sustainability of the projects. Subscription for water use by those involved in the projects will ease the financial constant, hence avail funds for expenses of the water system through purchase of relevant spares parts for the system. Once put in place the above state factors will enable high degree of the projects sustainability to enhance the intervention run at increased economic gain to the community.

\section{Recommendation}

The following recommendations are suggested for enhanced improvement of sustainability of irrigation projects: -

1. Capacity building of management committees through training on management, operation and maintenance of projects. 
2. Management committee to be assisted by bodies such as National government in setting tariffs for water consumption fees to be used for repairs and maintenance of water systems. This will make BUDUBI IRRIGATION PROJECT self-reliant.

3. BUDUBI to be assisted in getting outlet of affordable spare parts, this can be done by networking these outlets by relevant leaders.

4. The government to put in place policy to ensure sustainable and efficient utilization of water resource.

5. Environmental and climate change to be considered in the design for water supplies to ensure water sustainability in the long run.

\section{References}

1. Brundtland (2014). Green Cities, Growing Cities, Just Cities? Urban planning and the Contradictions of Sustainable Development. Journal of the American Planning Association, New Jersey.

2. Carrol Richardson, (2012); Yerman B., (2014)."Sustainability of projects: Combining qualitative and quantitative research in developing 'indicators' of sustainability". International Journal of Social Research Methodology.

3. Deogratias, S. (2013). Community participation and sustainability of national water projects: The case study of Chalinze Water Supply Project in Bagamoyo district.

4. Diana, N. (2009). Management and Regulation for Sustainable Water Supply Schemes in Rural Communities. Tanzania.

5. FAO(2015). FAO Statistical year book 2015: Asia and the Pacific Food and Agriculture

6. Gallagher, A.; Johnson, D.; Glegg, G. and Trier, C. (2004). Construct of sustainability in coastal zone management. Marine Policy, 28: 249-255.

7. Irungu, G.W. \&Makori, M.(2016). Determinants of performance of agricultural projects in Kenya: a case of Nyeri county. The Strategic Journal of Business \& Change Management, 3 (26), 462-480.

8. Karanja, G. (2013). Influence of management practices on sustainability of youth income generating projects in Kangema District, Murang'a County, Kenya. International Journal of Education and Research, 2(2), 1 - 12.

9. Kothari, C. (2011). Research methodology: Methods \& techniques (2nd Ed).New Delhi, India: New age International Publishers.

10. MINAGRI (2015). Strategies for increasing on-farm productivity levels and reducing yield gaps. Presentation at the National Public Policy Dialogue organized by the Rwanda Civil Society Platform, Kigali, Rwanda.

11. Mugenda, O. M. \&Mugenda, A. G., (2003). Research methods: quantitative \& qualitative approaches. Nairobi: African Centre for Technology Studies.

12. Polnac, R., \&Pomerey, R. S. (2015). Factors influencing the sustainability of integrated coastal management projects in Phillipines and Indinesia oceans and coastal management. British Journal of Economics, Finance and Management Science, 6 (2), 37 - 47.

13. Redclift, (2010). "Appropriate Technology for Socioeconomic Development in Third World Countries". The Journal of Technology Studies.

14. Thilmany, J., (2014). Linking up: Successfully combining project and product management. International Review of Management and Business Research, 3(2), 78-85.

15. USAID. (2009). The sustainability of donor-assisted rural water supply projects. United states : USAID.

16. (World Bank, 2017).

17. World Commission on Environment and Development (WCED) (1987), "Our common future", Oxford University Press, Oxford.

18. Yamane, T. (1967). Statistics. An Introductory Analysis, 2nd Ed., New York: Harper and Row. 